\title{
Apicoaortic valved conduit: Potential for progress?
}

Ulf Lockowandt, MD, PhD

From the Department of Cardiothoracic Surgery and Anesthesiology, Karolinska University Hospital, Stockholm, Sweden.

Supported by grants from the Mats Kleberg Foundation.

Received for publication March 10, 2006; revisions received June 24, 2006; accepted for publication July 7, 2006

Address for reprints: Ulf Lockowandt, MD, $\mathrm{PhD}$, Department of Cardiothoracic Surgery and Anesthesiology, Karolinska University Hospital, 17176 Stockholm, Sweden (E-mail: ulf.lockowand@karolinska.se).

J Thorac Cardiovasc Surg 2006;132:796-801 $0022-5223 / \$ 32.00$

Copyright (๑) 2006 by The American Association for Thoracic Surgery

doi:10.1016/j.jtcvs.2006.07.008
Objective: The number of elderly patients who require aortic valve replacement is growing, as is the increase of complicating factors, such as previous coronary bypass grafting and atherosclerotic disease of the ascending aorta. An uncommon surgical option to aortic valve replacement is the apicoaortic valved conduit. In this article the techniques and outcomes of 13 cases of apicoaortic valved conduit insertions in high-risk patients are described.

Methods: From 2002 through 2005, 13 patients (mean age, $75 \pm 8.7$ years; 8 men) with severe calcific aortic stenosis had insertions of an apicoaortic valved conduit because of a porcelain aorta $(n=4)$, previous coronary bypass grafting $(n=6)$, or both $(n=3)$. The off-pump technique was used in 9 patients, and a heparinized miniextracorporeal circulation system was used in 4 patients. Follow-up time was 6 to 33 months.

Results: Mean intensive care stay was $2 \pm 2.7$ days, and mean hospital stay was $12 \pm 8$ days. The 30-day mortality was $15 \%$ ( 2 patients; postoperative days 3 and 28 , both caused by myocardial infarction). Mortality later than 30 days postoperatively was $23 \%$ ( 3 patients; postoperative day 45 caused by bilateral pulmonary bleeding because of pneumonia, postoperative day 56 caused by myocardial infarction, and postoperative day 81 caused by pneumonia). The remaining 8 patients were doing well, all in New York Heart Association class I or II at follow-up, with echocardiography showing a low gradient over the valved conduit.

Conclusions: The apicoaortic valved conduit in high-risk patients undergoing aortic valve replacement remains a feasible option, with a substantial potential for technical development and progress.

$\mathrm{T}$ he number of elderly patients who require aortic valve replacement (AVR) is steadily growing. A consequence of this is the increase of complicating factors, such as previous coronary artery bypass grafting (CABG) with patent grafts and atherosclerotic disease of the ascending aorta. These risk factors have sometimes made conventional AVR an extremely high-risk venture. On occasion, the patients have been judged inoperable.

The most consistent risk factor for ascending aortic atherosclerosis is patient age. ${ }^{1}$ One third of patients older than 80 years who undergo cardiac surgery have important ascending aortic atherosclerosis. ${ }^{2}$ Conventional AVR requires both cardiopulmonary bypass $(\mathrm{CPB})$ and manipulation of the ascending aorta. It has been reported that atheroembolic events occurred in $37 \%$ of patients with severe disease of the ascending aorta but only in $2 \%$ of patients without significant ascending aortic disease. ${ }^{1}$ Hypothermic circulatory arrest and different strategies to manage the ascending aorta have been used to improve the results in AVR in patients with a severely atherosclerotic aorta. Despite these surgical approaches, the postoperative stroke and mortality rates remain high. ${ }^{3,4}$

In AVR after previous $\mathrm{CABG}$, the main intraoperative problems consist of re-entry, damage to patent grafts, and difficulty achieving sufficient myocardial protection. Several authors report an early mortality in AVR after previous CABG 


\section{Abbreviations and Acronyms \\ $\mathrm{AAVC}=$ apicoaortic valved conduit \\ AVR = aortic valve replacement \\ $\mathrm{CABG}=$ coronary artery bypass grafting \\ $\mathrm{CPB}=$ cardiopulmonary bypass}

of $17 \%$ to $18 \% .^{5}$ The incidence of left internal thoracic artery graft injury varies from $5 \%$ to $38 \% .^{6,7}$ In one study $40 \%$ of the patients sustained a perioperative myocardial infarction as a consequence of left internal thoracic artery injury. ${ }^{6}$ There are various options suggested to facilitate AVR after CABG, including deep hypothermia, beatingheart procedures, and endovascular techniques. In a systematic review of these alternative techniques, it was not possible to establish the superiority of any procedure over the others or whether an overall decrease in mortality could be achieved. $^{5}$

The apicoaortic valved conduit (AAVC) avoids re-entry through the sternum, injury to patent grafts, and manipulation of the ascending aorta. The use of an AAVC was first used clinically by Sarnoff and colleagues. ${ }^{8}$ The method has since then been rare, mostly used in pediatric patients ${ }^{9}$ but also in adult patients with stenotic calcified aortic valves in high-risk circumstances, such as previous cardiac surgery. ${ }^{10}$ Various studies with a limited number of patients have demonstrated good long-term results with working hemodynamics. ${ }^{11,12}$ With the exception of some of the pediatric cases, these operations have been performed with CPB. In addition, Vassiliades ${ }^{13}$ has described a technique for offpump AAVC insertion in 3 adult patients.

The objective of this article is to evaluate different techniques and the outcome of 13 cases of AAVC insertions in high-risk and often elderly patients with stenotic aortic valves. Of these procedures, 9 were performed off pump, which, to our knowledge, is the largest series to date reported of this technique. Four operations were performed with a heparinized miniextracorporeal circulation system.

\section{Methods}

This study was approved by the Ethics Committee of the Karolinska Hospital, and the patients were operated on after informed consent. If not otherwise stated, all data are presented as means \pm standard deviations.

Thirteen patients (mean age, $75 \pm 8.7$ years; 8 men) underwent insertions of AAVCs from 2002 through 2005. All patients had severe calcific aortic stenosis, and all were in New York Heart Association class III or IV. The mean pressure gradient was $52 \pm$ $17 \mathrm{~mm} \mathrm{Hg}$, with a mean aortic orifice area of $0.63 \pm 0.15 \mathrm{~cm}^{2}$. All but 3 patients had a good left ventricular function, with an ejection fraction of $55 \%$ or more. Two patients had a left ventricular ejection fraction of $30 \%$, and 1 had an ejection fraction of $25 \%$. Only one of the patients (ejection fraction of $30 \%$ ) had a dilated left ventricle, with an end-diastolic diameter of $54 \mathrm{~mm}$. All patients had dyspnea, 2 had episodes of pulmonary edema, and 3 had a clinical presentation with frank syncope. Two patients had been denied surgical intervention at other institutions, and 1 had undergone sternotomy at another hospital, was found to be inoperable, and then underwent chest closure. A porcelain aorta was present in

TABLE 1. Patients' characteristics with preoperative data and results

\begin{tabular}{|c|c|c|c|c|}
\hline Patient age (y) & Sex & $\begin{array}{l}\text { Severely calcified ascending } \\
\text { aorta }\end{array}$ & $\begin{array}{l}\text { Previous CABG with patent graft/grafts } \\
\text { close to backside of sternum }\end{array}$ & Other major risk factors \\
\hline 81 & M & $Y$ & $\mathrm{~N}$ & Poor LV, severe extracardiac arteriopathy \\
\hline 79 & M & Y & CABG, 1984 & Poor LV, severe extracardiac arteriopathy \\
\hline 69 & M & Y & CABG, 1977; CABG, 1992 & $\begin{array}{l}\text { Severe extracardiac arteriopathy, chronic } \\
\text { pulmonary disease }\end{array}$ \\
\hline 63 & $\mathrm{~F}$ & Y & $\mathrm{N}$ & \\
\hline 57 & M & $\mathrm{N}$ & CABG, 1993 & \\
\hline 82 & M & $\mathrm{N}$ & CABG, 1995 & \\
\hline 61 & $\mathrm{~F}$ & $\mathrm{~N}$ & CABG, 1993 & $\begin{array}{l}\text { Poor dilated LV function, severe } \\
\text { extracardiac arteriopathy, severe } \\
\text { diabetes, cerebral lymphoma }\end{array}$ \\
\hline 77 & $\mathrm{~F}$ & $\mathrm{~N}$ & CABG, 1998 & \\
\hline 77 & M & $\mathrm{N}$ & CABG, 1992 & \\
\hline 75 & M & $\mathrm{N}$ & CABG, 1997 & Poor nutritional state \\
\hline 83 & $\mathrm{M}$ & $Y$ & CABG, 1994 & \\
\hline 84 & $\mathrm{~F}$ & Y & $\mathrm{N}$ & $\begin{array}{l}\text { Severe extra cardiac arteriopathy, } \\
\text { preoperative kidney failure }\end{array}$ \\
\hline 81 & $\mathrm{~F}$ & Y & $\mathrm{N}$ & Severe extracardiac arteriopathy \\
\hline
\end{tabular}

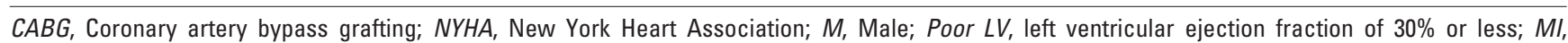
myocardial infarction; $F$, female. 
4 cases, 6 had previous coronary bypass grafting, and 3 had both. For further patient characteristics, see Table 1.

In addition to routine preoperative investigations, such as coronary angiography and echocardiography, computed tomography of the descending aorta was carried out to asses the possibility of performing the distal anastomosis of the conduit because severe atheroma of the descending aorta makes the procedure inadvisable. Furthermore, also regarded as contraindications were an aortic regurgitation of greater than I to II/IV and thrombus material in the left ventricular apex.

The off-pump technique was used in 9 patients, and a heparinized miniextracorporeal circulation system was used in 4 patients. Anesthesia was induced, and intubation was performed with a double-lumen endotracheal tube for single-lung ventilation. Heparin at a dose of $150 \mathrm{U} / \mathrm{kg}$ was administered in the off-pump group, as well as in the operations including a heparinized miniextracorporeal circulation system. A cell saver (Electa; Dideco, Sorin Group, Modena, Italy) was used. Access to the descending aorta and the apex of the heart was obtained by performing a low thoracotomy through the sixth intercostal space. The left lung was deflated, the pulmonary ligament was divided between the 2 ligatures, and the left lung was mobilized cranially to ensure access to the aorta. A partial occluding clamp was applied after the pleura was incised over the distal descending aorta. The distal end of the valved conduit (Hancock Bioprosthetic Valved Conduit, $22 \mathrm{~mm}$; Medtronic, Minneapolis, Minn) was attached to the aorta with a 3-0 nonabsorbable suture. By opening the pericardium and fixating it to the chest wall, an excellent exposure of the apex was achieved. The apex of the left ventricle was investigated with an echocardiographic probe (Acuson AV5, Acuson Sequoia C512; Siemens Medical Solutions Malvern, Pa) to avoid thin scarred myocardium and thrombus material and to keep clear of the septum and papillary muscles. The echocardiographic investigation did not change the approach from off pump to on pump in any of the cases. By using a surgical marker, the circumference and intended position of a Hancock Apical Left Ventricular Connector (22 mm; Medtronic) was marked on the apex. The position was chosen slightly anterior and lateral to the apex, keeping some distance to the distal end of the left anterior descending artery. The end of the connector is rigid and angled $90^{\circ}$, which makes it easy to attach to the valved conduit in a later stage. Taking great care, the circumference of the intended position was then encircled with deep muscular bites entering and exiting the epicardium with plegeted 2-0 Ethibond sutures on atraumatic V-7 or $\mathrm{MH}$ needles (Ethicon Inc, Norderstedt, Germany). The mattress sutures were passed through the collar of the connector, and the connector was lowered toward the heart. The sutures were kept aside to expose the apex. A stab wound was performed, the bleeding was digitally controlled, and the tip of the coring device (Hancock Model 1701A, Trocar Blade, $22 \mathrm{~mm}$; Medtronic) was pushed into the left ventricle. By using the trocar blade, a core of ventricular muscle was removed, and the connector was quickly slid into place. The interrupted sutures were securely tied. With a running 3-0 nonabsorbable suture, the distal end of the apical connector was attached to the valved conduit, and the graft was deaired. Finally, FloSeal (Baxter International Inc, Deerfield, Ill) was applied to all suture lines. The conduit was straightforwardly positioned without kinking, following the lateral aspect of the pericardium medial to the left lower lobe. Tubes for drainage were placed, and the chest was closed.

Four patients were circulatory supported with a heparinized miniextracorporeal circulation system (AFFINITY NT Oxygenator, Carmeda BioActive Surface, Bio-Pump Plus Centrifugal Blood Pump; Medtronic). The right femoral vein was used for

TABLE 1. Continued

\begin{tabular}{lccl}
\hline $\begin{array}{l}\text { Symptoms other than } \\
\text { dyspnea (NYHA III) }\end{array}$ & $\begin{array}{c}\text { Interrupted operation at other institution } \\
\text { because of porcelain aorta }\end{array}$ & $\begin{array}{c}\text { Denied operation at } \\
\text { other institution }\end{array}$ & Results \\
\hline Angina & $\mathrm{N}$ & $\mathrm{N}$ & $\begin{array}{c}\text { Died day } 28 \text { of MI } \\
\text { Well at } 33 \text { mo } \\
\text { Well at } 31 \text { mo }\end{array}$ \\
& $\mathrm{N}$ & $\mathrm{N}$ & Well at 20 mo \\
& $\mathrm{N}$ & $\mathrm{N}$ & Well at 12 mo \\
& $\mathrm{N}$ & $\mathrm{Y}$ & Died day 56 of MI \\
& $\mathrm{N}$ & $\mathrm{N}$ & Well at 10 mo \\
Angina & & $\mathrm{N}$ & \\
Pulmonary edema & $\mathrm{N}$ & $\mathrm{N}$ & Well at 10 mo \\
& $\mathrm{N}$ & $\mathrm{N}$ & Well at 9 mo \\
Syncope & $\mathrm{N}$ & $\mathrm{N}$ & Reoperation day 53 because of infection, \\
& $\mathrm{N}$ & $\mathrm{N}$ & Died day 81 of pneumonia \\
Angina & $\mathrm{N}$ & $\mathrm{N}$ & Died day 45 of pneumonia \\
Syncope & & Well at 6 mo
\end{tabular}


venous access, and the right femoral artery (in one case the graft attached to the descending aorta) was used for arterial access. The extracorporeal system was complemented with a cell saver (Electa, Dideco). The extracorporeal system was started at the beginning of the manipulation of the left ventricular apex and terminated when flow was established in the conduit.

Follow-up was performed during outpatient visits, including chest radiography and echocardiography, at 3, 6 and 12 months and then yearly. The anticoagulation regimen for all patients was 3 months of warfarin. Follow-up time was 6 to 33 months.

\section{Results}

Mean intensive care unit stay was $2 \pm 2.7$ days, and mean hospital stay was $12 \pm 8$ days. Mean operation time was $208 \pm 64$ minutes, and mean bypass time (in 4 patients) was $48 \pm 13$ minutes. Mean perioperative bleeding was $3060 \pm$ $1700 \mathrm{~mL}$ (off-pump, $2440 \pm 933 \mathrm{~mL}$; on-pump, $4450 \pm$ $2197 \mathrm{~mL}$ ), and mean postoperative bleeding was $812 \pm$ $420 \mathrm{~mL}$ (off-pump, $747 \pm 371 \mathrm{~mL}$; on-pump, $957 \pm 483 \mathrm{~mL}$ ).

In-hospital mortality was $8 \%$. One patient died on day 3 of a myocardial infarction, which was diagnosed at autopsy. In-house major complications were $31 \%$ (4 patients), including one case of kidney failure in a patient with known preoperative kidney failure (the postoperative failure did not require dialysis but did require a prolonged stay in the intensive care unit of 11 days). There were also 2 cases of reoperation because of bleeding, and in none of the cases could a bleeding point from the conduit or from the attachment of the conduit to the left ventricular apex or the descending aorta be found. There was one case of postoperative hyponatremia of unknown cause. The condition was difficult to treat and resulted in a prolonged hospital stay of 34 days. The patient was well at discharge, and at follow-up 6 months postoperatively, the patient had no deficits of sodium. Six patients had benign, self-terminating ventricular arrhythmias on the first postoperative days.

Postdischarge mortality was $30 \%$ (4 patients). One patient died on day 28 of a myocardial infarction that caused a partial dehiscence of the conduit from the left ventricular apex and a subsequent bleed. The cause of death was established with a postmortem examination. One patient died on day 45 of bilateral pulmonary bleeding because of pneumonia, and the postmortem examination showed an intact conduit. One patient died on day 56 of a myocardial infarction diagnosed on the basis of electrocardiography, enzymes, and clinical presentation. No autopsy was performed. There was 1 death on day 81 of pneumonia, and autopsy showed an intact conduit. This patient had been readmitted on day 53 with signs of infection and dyspnea. Investigations revealed a dehiscence of the conduit from the left ventricular apex, with adhesions creating a false aneurysmlike condition. At reoperation, the cause of the dehiscence was found to be an infectious process, with frank pus around the proximal part of the conduit close to the heart. The conduit could be reattached to the heart and wrapped with a flap of omentum. The patient was discharged on day 8 and was well with a normalized blood count.

Mean postoperative time of echocardiography evaluation was $16.4 \pm 9.8$ months. Left ventricular function did not change after the operation. The good left ventricular function preoperatively remained good. The 3 patients displaying reduced left ventricular ejection fraction continued doing so at follow-up. There was no reduction in end-diastolic diameter in the only patient with a left ventricular dilatation. No relation could be detected between preoperative ventricular function and mortality. Postoperatively, only 1 patient had a small antegrade flow through the native valve; the other 12 had none or a hardly detectable antegrade flow through the stenosed valve. The pressure gradient across the valved conduit was difficult to estimate. However, the flow velocity was low, $1.4 \pm 0.3 \mathrm{~m} / \mathrm{s}$, corresponding to a gradient of about $5 \mathrm{~mm} \mathrm{Hg}$. At follow-up, the surviving patients were doing excellent, and all were in New York Heart Association class I or II. There were no known thromboembolic events. For results, also see Table 1.

\section{Discussion}

Despite suggested modifications of conventional surgical intervention in AVR after CABG or in the presence of a severely calcified ascending aorta, mortality remains high. ${ }^{3-5}$ Some of these surgical adjustments, such as deep hypothermic arrest and replacement of the ascending aorta, add complexity and risk on their own to these often elderly and fragile patients. In this setting the search for methods improving the results continues to be a justifiable undertaking.

The most commonly used method for AAVC placement is using CPB either in the arrested or fibrillating heart. Except for some single case reports, there are only 2 articles describing a more systematic approach to an off-pump technique. Khanna and coworkers ${ }^{9}$ operated on 6 children off pump, and Vassiliades ${ }^{13}$ used a refined procedure in 3 adult patients. By inserting the AAVC off pump, the detrimental effects of both CPB and global cardiac ischemia are avoided. Several long-term follow-ups have demonstrated that the AAVC insertion effectively lessens the left ventricular-aortic pressure gradient, improves ventricular function, and maintains normal systemic blood flow. ${ }^{11,12,14}$

Challenging in the operations presented in this article was the intraoperative bleeding, which did not decrease with experience. The key moment of blood loss was at the time of the coring and the securing of the connector to the myocardium, making a stand-by for rapid transfusion fairly unproblematic. Possibly the blood loss during the securing could be reduced with a smaller coring device, but on the other hand, the insertion would most likely become more demanding. The heart was arrested in 1 patient by administering a rapid intravenous infusion of $6 \mathrm{mg}$ of adenosine to 
simplify the insertion. However, in this patient the heart restarted with considerable difficulty after the substantial blood loss and with the connector not yet attached to the graft (ie, without afterload reduction). When using this approach or rapid ventricular pacing, the connector has to be attached to the graft before the insertion of the connector into the apex to achieve swift afterload reduction.

A heparinized miniextracorporeal circulation system was used in the last 4 patients to increase surgeon comfort and to make potential complications more controllable. In this group the bleeding was not reduced, but the systemic circulation was better controlled throughout the phase of insertion and attachment of the connector.

This is an observational clinical report, including 2 different techniques of a surgical method continuously generating experience back to the surgical team throughout the study. There is no control group. The possibility to determine the superiority of one surgical technique over another is thereby limited. However, it is probably not erroneous to claim that the off-pump technique is presumably less traumatic to these frail patients, whereas the on-pump procedure provides greater security should something go wrong.

There are potentials for developing the attachment of the conduit to the apex, making it a reproducible, safer, and less bloody part of the operation, either on or off pump. One option is the attractive Seldinger-like technique described by Vassiliades. ${ }^{13}$ A further technique currently developed at our unit consists of a sewing ring secured to the left ventricular apex before removing a myocardial core of the left ventricular apex. The conduit is then inserted into the left ventricular cavity and secured to the ring. This method is similar to that used when deploying a Jarvik left ventricular assist device. ${ }^{15}$

There were no perioperative deaths in either group, but there were 5 (38\%) deaths in 90 days. This small material makes it unfeasible to draw any certain conclusions about patient selection. However, it is notable that the patients not surviving 90 days included some of the oldest patients, with a mean age of $81 \pm 3.2$ years compared with a mean age of $75 \pm 8.7$ years for the entire group.

Three patients succumbed to a myocardial infarction postoperatively. They all had known coronary artery disease. Experimental works regarding the placement of the distal anastomoses of left ventricular assist devices have shown that an attachment of the pump with pulsative flow to the descending aorta is associated with increased flow stagnation in the ascending aorta. ${ }^{16,17}$ In the patients presented in this article, no more than one had a residual, small antegrade flow through the stenosed native aortic valve, and in the remaining 12 patients, there was hardly any antegrade flow through the native valve, making a contribution to the coronary flow this way implausible. Until further investigations show otherwise, patients with coronary artery disease should perhaps only be accepted with caution for AAVC insertion.

In conclusion, the majority of patients were doing fine at follow-up. Complications, such as postoperative bleeding, infection, and benign arrhythmias, were manageable. The 90-day mortality of $38 \%$ is notable but not entirely unexpected among these sometimes very elderly and weak patients. Autopsies did not show malfunctioning of any of the conduits. The AAVC, using either an off-pump technique or a heparinized miniextracorporeal circulation system in highrisk patients undergoing AVR, is therefore a feasible alternative to conventional surgical intervention that is cautiously used in patients with coronary artery disease. Furthermore, the potential for technical development and progress in this method is substantial.

I acknowledge the great skills of Jan Liska, MD, Department of Cardiothoracic Surgery and Anesthesiology, Karolinska University Hospital, for being of utmost importance in developing the surgical techniques presented.

\section{References}

1. Blauth CI, Cosgrove DM, Webb BW, Ratliff NB, Boylan M, Piedmonte MR, et al. Atheroembolism from the ascending aorta. An emerging problem in cardiac surgery. J Thorac Cardiovasc Surg. 1992;103:1104-11

2. Davila-Roman VG, Murphy SF, Nickerson NJ, Kouchoukos NT, Schechtman KB, Barzilai B. Atherosclerosis of the ascending aorta is an independent predictor of long-term neurologic events and mortality. J Am Coll Cardiol. 1999;33:1308-16.

3. Kouchoukos NT, Wareing TH, Daily BB, Murphy SF. Management of the severely atherosclerotic aorta during cardiac operations. J Card Surg. 1994;9:490-4.

4. Gillinov AM, Lytle BW, Hoang V, Cosgrove DM, Banbury MK, McCarthy PM, et al. The atherosclerotic aorta at aortic valve replacement: surgical strategies and results. J Thorac Cardiovasc Surg. 2000; 120:957-63.

5. Shanmugam G. Aortic valve replacement following previous coronary surgery. Eur J Cardiothorac Surg. 2005;28:731-5.

6. Gillinov AM, Casselman FP, Lytle BW, Blackstone EH, Parsons EM, Loop FD, et al. Injury to a patent left internal thoracic artery graft at coronary reoperation. Ann Thorac Surg. 1999;67:382-6.

7. Ivert T, Ekestrom S, Peterffy A, Welti R. Coronary artery reoperations. Early and late results in 101 patients. Scand J Thorac Cardiovasc Surg 1988;22:111-8.

8. Sarnoff SJ, Donovan TJ, Case RB. The surgical relief of aortic stenosis by means of apical-aortic valvular anastomosis. Circulation. 1955;11 564-74.

9. Khanna SK, Anstadt MP, Bhimji S, Bannan MM, Mawulawde K, Zumbro GL, et al. Apico-aortic conduits in children with severe left ventricular outflow tract obstruction. Ann Thorac Surg. 2002;73:81-6.

10. Cooley DA, Lopez RM, Absi TS. Apicoaortic conduit for left ventricular outflow tract obstruction: revisited. Ann Thorac Surg. 2000;69: 1511-4.

11. Nihill MR, Cooley DA, Norman JC, Hallman GL, McNamara DG Hemodynamic observations in patients with left ventricle to aorta conduit. Am J Cardiol. 1980;45:573-82.

12. Fogel MA, Rychik J, Chin AJ, Hubbard A, Weinberg PM. Evaluation and follow-up of patients with left ventricular apical to aortic conduits with $2 \mathrm{D}$ and $3 \mathrm{D}$ magnetic resonance imaging and Doppler echocardiography: a new look at an old operation. Am Heart J. 2001;141:630-6.

13. Vassiliades T. Off-pump apicoaortic conduit insertion for high-risk patients with aortic stenosis. Eur J Cardiothorac Surg. 2003;23:156-8. 
14. Renzulli A, Gregorio R, De Feo M, Ismeno G, Covino FE, Cotrufo M. Long-term results of apico-aortic valved conduit for severe idiopathic hypertrophic subaortic stenosis. Tex Heart Inst J. 2000;27:24-8.

15. Siegenthaler MP, Martin J, Frazier OH, Beyersdorf F. Implantation of the permanent Jarvik-2000 left-ventricular-assist-device: surgical technique. Eur J Cardiothorac Surg. 2002;21:546-8.
16. Litwak KN, Koenig SC, Tsukui H, Kihara S, Wu Z, Pantalos GM. Effects of left ventricular assist device support and outflow graft location upon aortic blood flow. ASAIO J. 2004;50:432-7.

17. DiGiorgi PL, Smith DL, Naka Y, Oz MC. In vitro characterization of aortic retrograde and antegrade flow from pulsatile and non-pulsatile ventricular assist devices. J Heart Lung Transplant. 2004;23:186-92. 